\title{
ANALISIS FAKTOR YANG MEMPENGARUHI MINAT WISATAWAN DOMESTIK BERKUNJUNG KE BALI
}

\author{
AA. Bagus Putu Widanta ${ }^{1}$, AA. Ketut Ayuningsasi ${ }^{2}$ \\ Email: awidanta@gmail.com ${ }^{1}$, ayu_ning_sasi@yahoo.com² \\ Fakultas Ekonomi dan Bisnis, Universitas Udayana
}

\begin{abstract}
Domestic tourists contribute no less than foreign tourists to Bali tourism. The number of domestic tourists visits far exceeds than the number of foreign tourists, which is has a significant impact on Bali's economic growth. The prospect of domestic tourists is very large, it is necessary to pay attention and analyze the factors that influence the interest of domestic tourist revisit to Bali. Factors that attract investment, people (tourists) and industry to an area, namely; image is the beliefs, ideas and expressions that a person has towards an area; attraction marketing/attraction of tourist destinations is an important reason for tourists, investors and capital to visit a place; infrastructure marketing is the availability of facilities and infrastructure that can attract people, investment and capital; and people marketing strategy to promote the area by marketing people, for example the attitude of the community: how much openness of the local community (regional) to elements (people, investment, industry, products) from other area; Price is a number of expenses spending during visit an area, including the price of accommodation, restaurants, transportation and performances in an area. Image, infrastructure marketing, attraction marketing, people marketing, have a positive and significant effect, except that price has a positive and insignificant effect on the interest of domestic tourist revisit to Bali. Identification of variables that influence the interest of domestic tourists to be a reference for decision making and policies for related parties to develop the direction of tourism policies on Bali in particularly and Indonesia in generally.
\end{abstract}

\begin{abstract}
Abstrak: Wisatawan domestik memberikan kontribusi yang tidak kalah besar dengan wisatawan mancanegara terhadap pariwisata Bali. Jumlah kunjungan wisatawan domestik jauh melampaui kunjungan wisatawan mancanegara, memberikan dampak yang signifikan terhadap pertumbuhan ekonomi Bali. Prospek wisatawan domestik (wisdom) yang sangat besar perlu mendapat perhatian dan dilakukan analisis faktor yang mempengaruhi minat wisdom untuk berkunjung ke Bali. Faktor yang menarik investasi, orang (wisatawan) dan industri kesuatu daerah yaitu: image (citra) adalah kepercayaan, ide dan ekspresi yang dimiliki seseorang terhadap suatu daerah; atraction marketing/atraksi (daya tarik) destinasi wisata merupakan alasan penting untuk wisatawan, investor dan modal datang ke suatu tempat; infrastructure marketing adalah tersedianya sarana dan prasarana yang mampu menarik orang, investasi dan modal; dan people marketing strategi memasarkan daerah dengan memasarkan orang misalnya sikap masyarakat: seberapa jauh keterbukaan masyarakat lokal (daerah) terhadap unsur-unsur (orang, investasi, industri, produk) dari luar; harga adalah sejumlah pegeluaran yang dikeluarkan untuk berkunjung kesuatu daerah, termasuk di dalamnya harga akomodasi, restoran, transportasi dan pertunjukan disuatu daerah. Image, infrastructure marketing, attraction marketing, people marketing berpengaruh positif dan signifikan, kecuali harga berpengaruh positif dan tidak signifikan terhadap minat wisatawan domestik untuk berkunjung kembali ke Bali. Identifikasi variabel yang mempengaruhi minat wisatawan domestik untuk bisa menjadi referensi pengambilan keputusan dan kebijakan bagi pihak terkait untuk pengembangan arah kebijakan pariwisata bali khususnya dan Indonesia umumnya.
\end{abstract}

Keywords: domestic tourists, bali, image, infrastructure marketing, attraction marketing, people marketing, enlightenment, price. 


\section{PENDAHULUAN}

Struktur perekonomian Bali memiliki karakteristik yang berbeda dibandingkan dengan daerah lain di Indonesia. Bali mengandalkan Industri pariwisata di dalam mengejar pertumbuhan ekonominya. Industri pariwisata merupakan leading sector dan menjadi output bagi aktivitas sektor lainnya. Industri pariwisata memberikan kaitan ke depan dan ke belakang terhadap sektor lainnya. Sektor pertanian, peternakan, angkutan, dan konstruksi. Dari sembilan sektor di provinsi Bali hanya terdapat empat sektor yang teridentifikasi menjadi sektor basis di tunjukan oleh nilai location queuotient lebih besar dari satu yaitu sektor pertanian $(\mathrm{LQ}=1,18)$, sektor perdagangan hotel dan restoran $(\mathrm{LQ}=1,94)$, sektor transportasi dan komunikasi $(\mathrm{LQ}=1,69)$ dan sektor jasa dengan (LQ=1,56) (Antara, 2016). Suatu sektor dikategorikan sebagai basis atau unggulan apabila sektor tersebut mampu bersaing dengan sektor yang sejenis di wilayah lain di Indonesia dengan kata lain mampu mengekspor/menjual produknya ke daerah lain di Indonesia. Sebagai salah satu sektor basis/unggulan Industri pariwisata perdagangan, akomodasi dan restoran menjadi sektor yang memiliki potensi untuk dikembangkan, karena akan memberikan sumbangan kepada daerah dari keunggulan sumber daya yang dimilikinya. Sumbangan Sektor pariwisata terhadap PDRB Provinsi Bali paling tinggi dibandingkan dengan sektor lain.

Pariwisata Indonesia berkembang dengan pesat, hal ini bisa dilihat dari jumlah kunjungan wisatawan yang terus meningkat setiap tahunnya baik wisatawan mancanegara maupun wisatawan domestik. Kunjungan wisatawan mancanegara menjadi sumber pendapatan untuk memperbaiki surplus neraca pembayaran Indonesia. Surplus neraca pembayaran menambah cadangan devisa negara yang dapat digunakan untuk membiayai pembangunan dan mengejar pertumbuhan ekonomi.

Peningkatan jumlah kunjungan wisatawan akan berdampak terhadap peningkatan pendapatan masyarakat sekitarnya. Perkembangan pariwisata yang pesat diikuti dengan pertumbuhan jumlah hotel dan restoran yang membawa dampak terciptanya lapangan pekerjaan. Tenaga kerja Bali baik formal maupun informal banyak terserap di Industri pariwisata yang terus berkembang.

Tabel 1. Jumlah Penyerapan Tenaga Kerja di Sektor Pariwisata di Kabupaten Kota Provinsi Bali

\begin{tabular}{lrrrrr}
\hline \multirow{2}{*}{ Kabupaten/Kota } & \multicolumn{5}{c}{ Penyerapan tenaga kerja di sektor pariwisata } \\
& \multicolumn{1}{c}{2013} & 2014 & \multicolumn{1}{c}{2015} & \multicolumn{1}{c}{2016} & \multicolumn{1}{c}{2017} \\
\hline Denpasar & 170.855 & 195.205 & 220.739 & 210.587 & 211.632 \\
Badung & 106.254 & 115.686 & 141.975 & 137.735 & 140.335 \\
Gianyar & 82.862 & 76.346 & 100.304 & 96.735 & 97.857 \\
Tabanan & 50.253 & 57.763 & 71.193 & 64.543 & 66.238 \\
Karangasem & 45.108 & 48.362 & 45.382 & 42.509 & 52.425 \\
Klungkung & 25.470 & 25.738 & 29.211 & 28.081 & 31.923 \\
Jembrana & 28.840 & 31.989 & 41.034 & 39.131 & 44.012 \\
Bangli & 20.186 & 18.899 & 24.742 & 19.020 & 19.273 \\
Buleleng & 96.114 & 88.324 & 93.495 & 91.126 & 96.398 \\
Total & 625.942 & 658.312 & 768.075 & 728.757 & 760.093 \\
Pertumbuhan & - & $5,17 \%$ & $16.6 \%$ & $-5,11 \%$ & $4,57 \%$ \\
\hline Sum & - & & &
\end{tabular}

Sumber: Badan Pusat Statistik Provinsi Bali, 2019.

Pada 2017 jumlah tenaga kerja Bali yang bekerja di sektor pariwisata sebanyak 760.093 orang dari total angkatan kerja yang sedang bekerja di Provinsi Bali di tahun 2017 sebanyak 2.490 .870 orang, yang berarti sebanyak 30,51 persen tenaga kerja Bali bekerja di sektor pariwisata. Jumlah kunjungan wisatawan mancanegara yang datang Indonesia dibandingkan dengan negara disekitar berada pada posisi keempat, dibawah Malaysia, Thailand, Singapura dan hanya sedikit diatas Vietnam, hal ini seharusnya memotivasi pemerintah dan instansi terkait untuk mengembangkan pariwisata Indonesia ke depan. 
Tabel 2. Perkembangan Kunjungan Wisatawan ke Bali

\begin{tabular}{lrrrr}
\hline Tahun & Mancanegara & $\begin{array}{c}\text { Perkembangan } \\
(\%)\end{array}$ & Domestik & $\begin{array}{c}\text { Perkembangan } \\
(\%)\end{array}$ \\
\hline 2012 & 2.892 .019 & 4,91 & 6.063 .558 & 6,84 \\
2013 & 3.278 .598 & 13,37 & 6.976 .536 & 15,06 \\
2014 & 3.766 .638 & 14,89 & 6.394 .307 & $-8,35$ \\
2015 & 4.001 .835 & 6,24 & 7.147 .100 & 11,77 \\
2016 & 4.927 .937 & 23,14 & 8.643 .680 & 20,94 \\
2017 & 5.697 .739 & 15,62 & 8.735 .633 & 1,06 \\
2018 & 6.070 .473 & 6,54 & 9.757 .991 & 11 '70 \\
2019 & 6.275 .210 & 3,37 & - & - \\
\hline
\end{tabular}

Sumber: Badan Pusat Statistik Provinsi Bali, 2019.

Luas daratan Bali yang hampir sebanding dengan Singapura, namun jumlah wisatawan mancanegara yang berkunjung ke Bali pada tahun 2018 sebanyak 6,01 juta orang ternyata berada jauh di bawah negara Singapura yang sebanyak 18,5 juta kunjungan wisatawan (kompas.com,2019). Diperlukan formulasi strategi pengembangan dan pemasaran pariwisata yang tepat untuk meningkatkan minat wisatawan mancanegara berkunjung ke Bali dan memperhatikan kunjungan wisatawan domestik yang selalu di atas jumlah kunjungan wisatawan mancanegara.

Kemajuan ekonomi, ilmu pengetahuan dan teknologi merubah pola konsumsi masyarakat di Indonesia dari pemenuhan kebutuhan primer dan sekunder (pemenuhan pangan dan sandang) menjadi pemenuhan kebutuhan tersier (rekreasi, wisata dan jasa lainnya) Generasi milenial dengan jenis pekerjaan yang baru menyebabkan mereka memiliki waktu luang yang lebih banyak dan memiliki kebebasan memilh lokasi untuk melakukan pekerjaannya. Fleksibelitas yang tinggi ini akan membuat generasi ini memiliki banyak waktu untuk berlibur, dan menjadi peluang untuk sektor pariwisata termasuk Pariwisata Bali. Wisatawan domestik yang berkunjung ke Bali datang dari berbagai pelosok kota dan kabupaten di wilayah Indonesia seperti Jakarta, Surabaya, Medan, Bandung, Jayapura, Pekanbaru, Manado, Mataram, Bima dan wilayah lainnya. Wisatawan domestik berkunjung ke Bali dengan berbagai tujuan seperti; berlibur, perjalanan bisnis, mengikuti seminar, rapat, konferensi, pendidikan, urusan pekerjaan maupun kebutuhan hobi dan olahraga.

Terdapat pilihan tujuan wisata lainya di berbagai wilayah di Indonesia selain Bali seperti; Jakarta, Kepulauan Riau, Yogyakarta,
Bandung, Lombok, Nusa Tenggara Barat dan Raja Ampat di Papua Barat yang menjadi kompetitor bagi Pariwisata Bali. Selain menghadapi persaingan dari dalam negeri pariwisata Bali juga menghadapi persaingan yang ketat dari pariwisata dari negara lain. Tidak sedikit wisatawan asal Indonesia yang berkunjung ke luar negeri. Tercatat dari data Singapore Tourism Board (2019) sebanyak 3,02 juta wisatawan Indonesia berkunjung ke Singapura sepanjang 2018 dan menduduki peringkat kedua dari daftar wisatawan mancanegara.

Menurut Erawan dalam Suarsana, (2003), kurangnya antisipasi terhadap kebijakan pariwisata akan menjebak pariwisata Bali kedalam kejenuhan dan kemungkinan berlakunya perubahan sikap (attitude) dari masyarakat lokal terhadap perkembangan pariwisata di daerahnya, yakni: tahap awal yaitu tahap "euphoria" dimana wisatawan dan investor diterima dengan antusias. Tahap berikutnya adalah "apathy" dimana wisatawan diterima sebagai sesuatu yang benar (taken for granted), dimana kontak dengan wisatawan besifat lebih formal; sampai kepada tahap permusuhan (antagonism) dimana kejengkelan masyarakat lokal dikemukakan secara terbuka, wisatawan dipandang sebagai pembuat masalah. Ekternalitas yang ditimbulkan dari Industri pariwisata Bali seperti masalah sampah, kemacetan yang parah dan berbagai masalah sosial dan keamanan yang jika tidak segera diatasi akan menjadi ancaman yang serius bagi keberlangsungan industri pariwisata Bali.

Diperlukan strategi yang tepat dalam mengemas produk wisata Bali agar pariwisata Bali mampu bersaing, menangkap peluang, memenangkan ancaman. Peningkatan keamanan Bali, promosi citra dan peningkatan produk (transportasi, fasilitas dan 
infrastruktur) akan memberikan kenyamanan dan menjadi informasi positif kepada wisatawan untuk berkunjung. Menurut Kuncoro (2014), ada empat strategi menarik investasi, orang (wisatawan) dan industri kesuatu daerah yaitu; image (citra) adalah kepercayaan, ide dan ekspresi yang dimilki orang terhadap suatu daerah; atraction marketing/atraksi (daya tarik) merupakan alasan penting untuk wisatawan, investor dan modal datang ke suatu tempat; infrastructure marketing adalah tersedianya saran dan prasarana yang mampu menarik orang, investasi dan modal; dan people marketing strategi memasarkan daerah dengan memasarkan orang misalnya sikap masyarakat: seberapa jauh keterbukaan masyarakat lokal (daerah) terhadap unsurunsur (orang, investasi, industri, produk) dari luar.

Perumusan kebijakan yang tepat diperlukan untuk meningkatan jumlah kunjungan wisatawan domestik ke Provinsi Bali sekaligus mempertahankan Bali sebagai tempat kunjungan favorit wisatawan domestik di Indonesia. Penelitian ini memiliki hipotesis bahwa image,infrastructure, attraction dan people marketing, dan harga berpengaruh terhadap minat wisatawan domestik untuk berkunjung ke Bali. Pernah dilakukan penelitian sejenis oleh beberapa peneliti. Penelitian Nuraeni (2014) menggunakan data primer dan 110 orang responden meneliti persepsi faktor-faktor wisatawan kunjung ulang ke Museum Ranggarwarsita Semarang. Dalam penelitian ini ditemukan bahwa variabel yang berpengaruh signifikan terhadap kunjung ulang adalah variabel promosi, variabel kualitas layanan dan variabel dayatarik wisata.Penelitian Nugraha (2018), penelitian menemukan bahwa bahwa variabel promosi online berpengaruh secara signifikan terhadap minat kunjungan wisatawan di Ramayana Ballet Purawisata di Mandira Bruga Yogyakarta. Rajesh (2013) meneliti tentang persepsi wisatawan, image tempat tujuan wisata kepuasan wisatawan terhadap destination loyalty. Hasil penelitian di studi awal menyebutkan bahwa persepsi wisatawan, image tempat tujuan wisata kepuasan wisatawan berpengaruh positif dan signifikan terhadap destination loyalty. Wang and Danish (2019) dalam studi empiris menemukan sektor pariwisata berpengaruh signifikan terhadap pertumbuhan ekonomi, walaupun parwisata menurunkan kualitas lingkungan hidup. Sedangkan people marketing berpengaruh terhadap minat wisatawan domestik untuk berkunjung ke Bali.

\section{METODE}

Penelitian ini akan mengkaji pengaruh image, infrastructure, attraction dan people marketing, dan harga terhadap minat wisatawan domestik untuk berkunjung ke Bali. Penelitian akan menggunakan metode kuantitatif dengan bantuan instrumen penelitian berupa kuisioner yang akan dibagikan kepada para responden penelitian serta wawancara berkaitan dengan variabel yang diteliti. Setelah tujuan penelitian ditetapkan dan beberapa pertanyaan sudah didefinisikan secara operasional, maka kuisioner sudah siap untuk dijadikan instrumen penelitian. Langkah selanjutnya adalah menentukan lokasi penelitian, responden dan teknik sampling dan kemudian persiapan penelitian lapangan. Tahap ini dilakukan dengan memberikan arahan kepada enumerator oleh tim peneliti. Tahap berikutnya adalah penyebaran kuisioner dibarengi dengan proses wawancara. Setelah 100 kuisioner terkumpul, maka akan dilakukan uji validitas dan reliabiltas instrumen penelitian. Jika instrumen sudah valid dan reliabel, maka tahap lanjut yang dapat dilakukan adalah mengumpulkan data dan menganalisisnya. Data akan dianalisis menggunakan analisis regresi dengan bantuan program SPSS dan langkah terakhir adalah menginterpretasikan dan membahas hasil analisis data yang telah didapatkan untuk dibuatkan kesimpulan dan saran.

Adapun identifikasi variabel dalam penelitian ini, variabel image,infrastructure, attraction dan people marketing dan harga sebagai variabel independen (X), minat wisatawan domestik untuk berkunjung kembali sebagai variabel dependen (Y), Untuk memudahkan mengukur dan menganalisis data penelitian, maka setiap variabel memiliki dimensi ataupun indikator yang dapat dijelaskan sebagai berikut:

1. Image di proksikan oleh citra pulau dewata di mata wisatawan.

2. Infrastructure marketing di proksikan oleh fasilitas jalan, transportasi, kualitas lingkungan, fasilitas akomodasi, 
restaurant, dan pelayana $\mathrm{n}$ wisatawan di Bali.

3. Vektor attraction marketing terdiri dari keindahan alam, sejarah, destinasi wisata alam, destinasi wisata buatan, monumen dan patung di Bali.

4. Vektor people marketing terdiri dari keramahan, kejujuran, keterbukaan terhadap wisatawan, kualitas SDM di Bali.

5. Harga dilihat dari keterjangkauan harga bagi wisatawan domestik yang berkunjung ke Bali.

Dalam mengumpulan data penelitian digunakan teknik gabungan wawancara dan kuesioner. Dalam wawancara dikumpulkan informasi yang relevan, seperti minat wisatawan berkunjung kembali ke Bali, image, Infrastruktur, atraksi, manusia dan keterjangkauan harga pariwisata Bali di mata wisatawan domestik. Dipersiapkan daftar pertanyaan yang dituangkan dalam kuisioner dengan menggunakan instrumen penelitian, dikumpulkan data primer dari responden wisatawan domestik.

Analisis statistik deskriptif digunakan untuk mendeskripsikan data yang telah terkumpul, sehingga diperoleh gambaran yang jelas tentang hasil penelitian. Analisis deskriptif terutama dimaksudkan untuk mengetahui karakteristik wisatawan domestik, gambaran umum wilayah penelitian dan persepsi wisatawan domestik berkaitan dengan variabel penelitian, yaitu image, infrastructure, attraction dan people marketing dan harga. Analisis data yang digunakan dalam penelitian ini adalah regresi linier berganda. Melalui suatu model regresi dapat diketahui pengaruh varianel bebas terhadap variabel terikat.

\section{HASIL DAN PEMBAHASAN}

Pengujian data pada penelitian ini menggunakan analisis regresi guna menguji pengaruh variabel dependen dan independen dalam penelitian ini. Adapun hasil analisis data dijelaskan sebegai berikut.

\section{Uji Kelayakan Model}

Uji statistik F digunakan untuk melihat pengaruh semua variabel bebas (X) yang dimasukan dalam model mempunyai pengaruh secara simultan terhadap variabel minat wisatawan domestik berkunjung kembali ke Bali (Y). Dapat dilihat nilai F hitung sebesar 27,304 lebih besar daripada $F$ tabel 3,17 maka
$\mathrm{H}_{0}$ dapat ditolak pada derajat kepercayaan 10 persen, dengan kata lain hipotesis alternatif diterima, yang menyatakan bahwa semua variabel independen; image, infrastruktur marketing, attraction marketing, people marketing dan harga secara simultan dan signifikan mempengaruhi wisatawan domestik yang berkunjung kembali ke Bali.

\section{Uji Signifikansi Individual (Uji-t)}

Uji-t dilakukan untuk menguji signifikansi hubungan antara variabel bebas (X) dan variabel terikat (Y), apakah variabel $\mathrm{X} 1, \quad \mathrm{X} 2, \mathrm{X} 3, \mathrm{X} 4$ dan $\mathrm{X} 5$ benar-benar berpengaruh terhadap individual secara individual atau parsial (Imam Ghozali, 2006). Uji-t menunjukkan seberapa jauh pengaruh variabel variabel independen; image, infrastruktur marketing, attraction marketing, people marketing secara parsial dan signifikan mempengaruhi wisatawan mancanegara berkunjung kembali ke Bali.

Hasil penelitian menunjukan tingkat signifikan dalam penelitian ini semua berada di bawah 0,10 derajat kepercayaan sebesar 10 persen, maka $\mathrm{H}_{0}$ dapat ditolak. Dengan kata lain menerima hipotesis alternatif, yang menyatakan bahwa semua variabel independen; image, infrastruktur marketing, attraction marketing dan people marketing secara parsial dan signifikan berpengaruh terhadap variabel dependen wisatawan mancanegara berkunjung kembali ke Bali. sedangkan Hraga berpengaruh potitif dan tidak signifikan terhadap wisatawan berkunjung kembali ke Bali.

Pengaruh siginifikan masing-masing penelitian dalam penelitian ini terlihat dari semua nilai sig. yang berada di bawah 0,10 (10 persen) dengan nilai masing-masing; image nilai Sig. sebesar 0,002 infrastruktur marketing dengan nilai Sig. sebesar 0,046 , attraction marketing dengan nilai Sig. sebesar 0,076, people marketing nilai Sig. sebesar 0,066 dan harga dengan nilai sig 0.404 . $\mathrm{Y}^{\prime}=-2,349+$ 0,311 image $\beta_{1}+0,073$ infrastructure $\beta_{2}+0,074$ attraction $\beta_{3}+0,193$ people $\beta_{4}+0,058$ Harga $\beta_{5}+\mathrm{ei}$

\section{Pengaruh Image Pariwisata Bali terhadap Minat Berkunjung Wisatawan Domestik Kembali ke Bali}

Hasil regresi penelitian menunjukkan bahwa Image/citra Bali berpengaruh positif dan siginifikan terhadap minat wisatawan 
domestik untuk berkunjung kembali ke Bali. Hasil ini sesuai dengan penelitian Chiu (2016) yang melihat pengaruh image tujuan wisata dan kepuasan wisatawan terhadap loyalitas wisatawan china yang berkunjung ke Korea. Hasil penelitian menunjukkan image kognitif mempengaruhi secara langsung image afektif dan berpengaruh positf dan signifikan terhadap kepuasan yang selanjutnya diprediksi meningkatkan loyalitas wisatawan.

Hasil peneyebaran kuisioner terhadap wisatawan domestik yang berkunjung ke Bali maupun yang mengisi secara daring dari google form ternyata di mata wisatawan Bali lebih dikenal sebagai seribu pura dengan skor paling tinggi dibandingkan dengan image yang lainnya. Hal ini seperti yang disampaikan salah satu wisatawan asal Jakata yang mengatakan mengenai hal yang paling menarik dan berkesan di Bali (Doddy, 2020): "Bali sangat indah dan terdapat tempat ibadah pura yang sangat indah arsitektur dan tamannya"

\section{Pengaruh Infrastructure Marketing terhadap Minat Berkunjung Wisatawan Domestik Kembali ke Bali}

Hasil Uji-t (parsial) menunjukkan hasil bahwa infrastruktur marketing berpengaruh positif dan siginifikan terhadap minat wisatawan domestik untuk berkunjung kembali ke Bali. Kelengkapan infrastukur menjadi pertimbangan utama wisatawan untuk berkunjung ke Bali. Infrastruktur yang lengkap dan berkualitas menanbah kenyamanan wisatawan domestik menikmati liburannya di Pulau Bali. Kelengkapan infrastruktur pendukung pariwisata Bali, diantaranya; fasilitas restaurant, pusat perbelanjaan, hotel, transportasi dan jalan, area parkir, fasilitas meeting dan lain-lain.

Hasil penelitian ini dikuatkan oleh penelitian Khadaroo (2007) menginvestigasi pengaruh transport infrastructure dalam mengembangkan tempat tujuan wisata, hasil penelitian menunjukkan wisatawan Amerika, Eropa dan Asia sensitif terhadap infrastruktur transportasi di pulau. Senada dengan penelitian Blazeska (2018) yang menyatakan terdapat pengaruh yang besar antara tourist infrastructure dengan kepuasan wisatawan yang berkunjung di Ohrid.

Hasil wawancara mendalam keluhan wisatawan tentang infrastruktur transportasi terlihat dari beberapa rekomendasi yang disampaikan dalam wawancara Doddy (2020) asal Jakarta dan Bayu (2020) asal Bandung memberikan rekomendasi "Hati-hati dengan kemacetan di Bali, bisa berjam-jam pada saat Tahun Baru, Bali perlu Tol untuk mengatasi kemacetan".

Infrastruktur transportasi (jalan memadai dan berkualitas) dan mendapat rangking skor yang rendah sebesar 360. Hal ini mengindikasikan perhatian pemerintah daerah terhadap infrastruktur transportasi masih sangat rendah. Pemerintah harus mulai memperhatikan infrastruktur jalan Bali yang lebih memadai untuk mengurai kemacetan yang mengganggu kenyamanan wisatawan domestik berkunjung ke Bali

\section{Pengaruh Atraction Marketing terhadap Minat Berkunjung Wisatawan Domestik Kembali ke Bali}

Atraction Marketing berpengaruh positif dan signifikan terhadap minat berkunjung wisatawan mancanegara kembali ke Bali. Obyek wisata Bali terkenal dengan daya tarik buatan (artificial attraction) yang direkayasa oleh campur tangan manusia dan dayat tarik/atraksi alam (natural attraction) yang merupakan anugrah dari Tuhan. Atraksi (daya tarik) merupakan alasan wsatawan, investor dan modal datang ke suatu tempat.

Untuk ataraksi Alam, Keindahan pantai dengan sunset dan sunrise nya mendapat skor paling tinggi, hal ini mengindikasikan keindahan panorama alam pantai, terbit dan terbenamnya matahari Bali menjadi aktivitas wisata yang paling disukai oleh wisatawan domestik. Karakter pantai Bali yang berbeda dengan didaerah lain di indonesia menyebabkannya menjadi salah satu obyek wisata yang paling diminati oleh wisatawan domestik.

Ketertarikan wisatawan tentang natural atraction tentang pantai yang indah terlihat dari beberapa opini yang disampaikan dalam wawancara dengan responden Sutrisna dan Taufik (2020) "sunset, pantai, suasana malam sangat berkesan, pemandangan pantai sangat indah".

Hasil kuisioner untuk atraksi buatan, responden wisatawan domestik paling menyukai keberadaan patung patung yang besar dan indah yang tersebar di hampir seluruh Kabupaten di Provinsi Bali, baik di obyek wisata maupun di persimpangan jalan jalan Bali. selain itu aktivitas olahraga air juga 
menjadi minat wisatawan domestik pada saat berkunjung ke Bali.

Ketertarikan wisatawan dengan artficial atraction patung-patung yang besar dan indah opini yang disampaikan oleh responden Meira (2020) dalam wawancara mengatakan "hal yang paling berkesan selama liburan di Bali adalah Tol Laut dan Patung Garuda Wisnu Kencana".

Pengaruh People Marketing terhadap Minat Berkunjung Wisatawan Mancanegara Kembali ke Bali

People marketing berpengaruh positif dan signifikan terhadap minat berkunjung wisatawan domestik kembali ke Bali. Profesionalitas dan kualitas pekerja, kebijakan pemerintah dan keterbukaan dan keramahan menjadi pertimbanagn wisatawan dalam memilih daerah tujuan wisatanya. Sejalan dengan penelitian Johann (2016) tentang studi pembanding pengalaman berlibur wisatawan senior yang mengatakan wisatawan senior sangat mengapresiasi pengalaman budaya, harga yang kompetitf dan keramahan penduduk. Dari skor yang diberikan oleh responden terlihat bahwa keterbukaan, terhadap kedatangan wisatawan mendapat skor paling tinggi. Seperti yang di sampakan oleh responden dalam wawancara Sari (2020) wisatawan domestik asal Jakarta "Orang Bali sangat terbuka dan terampil dalam menerima wisatawan".

Jhingan (2012) yang menyatakan terkadang yang menjadi keputusan orang untuk datang atau berinvestasi adalah keterbukaan masyarakat yang tidak anti bisnis. kualitas pekerja pariwisata Bali menjadi kunci utama wisatawan untuk berkunjung ke Bali. Sedangkan harga berpengaruh positif tetapi tidak signifikan terhadap minat wisatawan domestik berkunjung ke Bali.

\section{SIMPULAN DAN SARAN}

Image, infrastructure marketing, attraction marketing, people marketing, berpengaruh positif dan signifikan, kecuali harga berpengaruh positif dan tidak signifikan terhadap minat wisatawan domestik untuk berkunjung kembali ke Bali. Identifikasi variabel yang mempengaruhi minat wisatawan domestik dapat menjadi referensi pengambilan keputusan dan kebijakan pihak terkait untuk pengembangan arah kebijakan pariwisata bali khususnya dan Indonesia umumnya. 


\section{Kepustakaan}

BPS Bali, 2018, Bali Dalam Angka.

Suarsana Komang, (2003) Strategi Membangun Bekonomi Bali Menjawab Tantangan Global, hal 107. PT Bali Post, Denpasar

Kuncoro, Mudrajat,2014, Otonomi Daerah Menuju Era Baru Pembangunan Daerah,Erlangga, Yogyakarta

Nuraini, Belinda Sofia, 2014, Analisis atorfator Yang Mempengaruh Minat Kunjung Ulang Wisatawan Museum Ranggawarsita Semarang, jurnal Bisns Strategi 23 (1).

Rajesh, R, 2013, Impact Of Tourist Perceptions, Destination Image and Tourist Satisfaction On Destination Loyalty; A conseptual Model.Pasos. Revista De Turismo y Patrimonio cultural journal 11(3) hal.67-78.

Wang Zhaouhua anf danish, 2019, Dynamic relationship between tourism, economic groeth and environmental quality, Journal of sustainable Tourism, 3 (1) Pages;1928-1943.

Chiu Weisheng, 2016, The Influence of destination image and tourist satisfaction on tourist loyalty: a case study of chinese tourist in Korea, International Journal of Culture Tourism and Hospitality Research 10(2): 223-234.

Khadaroo Jameel, 2008, The Role of Transport Infrastructure in International Tourism Development: A Gravity Model Approach. Tourism Management 29 (5): 831-840.

Blazeska Daliborka, 2018, The Influence of Tourist Infrastructure on The Tourist Satisfaction in Ohrid, UTMS Journl of Economic 9(1): 85-93.

Johann Maria, 2016, Benchmarking Holiday experience: the case of senior tourists, Benchmarking An International Journal 23(7).

Jhinghan, M.L. 2012. Ekonomi Pembangunan dan Perencanaan. (Alih bahasa: D. Guritno). Jakarta. Rajawali Pers.

Antara, Made, (2016) Kebutuhan Investasi Sektor Basis Dan Non Basis Dalam Perekonomian Bali, media.neliti.com.

Anuar, Ahmad nazrin Aris, Ahmad, Habibah, Jusoh, Hamzah, Hussain, Mohd Yusof. 2012. The Roles of Tourism Towards
Deelopment of Tourist Friendly Destination Concept. Asian Social Science, 8(6), pp:146-155.

Bertan, Serkan, (2013) Visitors Perception Of A Tourism Destination: the case Of Pamukale.

Tourismos an International Multidiciplinary Journal of Tourism, 8 (1) hal. 115-132. Dinas Pariwisata Provinsi Bali, 2017, Statistik Pariwisata Bali.

Nugraha, Nada bangun, 2018, Pengaruh promosi Oline terhadap unjungan wisatawan Di Madra Baruga Yogyakarta, Skripsi, UIN Yogyakarta.

Nuraini, Belinda Sofia, 2014, Analisis atorfator Yang Mempengaruh Minat Kunjung Ulang Wisatawan Museum Ranggawarsita Semarang, jurnal Bisns Strategi 23 (1).

Sukirno Sadono, 2006, Ekonomi Pembangunan Proses, Masalah, dan Dasar Kebijakan, Kencana Prenada Media Group, Jakarta.

Suyana Utama, 2009, Aplikasi Kuantitatif, Ed. 3, Fakultas Ekonomi dan Bisnis, Denpasar.

Undang-Undang Republik Indonesia No 10 Tahun 2009 Tentang Kepariwisataan Januari 2009.Lembaran Negara Republik Indonesia Tahun 2009. Jakarta.

Yoeti, Oka A. 2001, Tours and Travel Management, Edisi 6, PT Pradnya Paramita, Jakarta.

https;//kompas.com diunduh 28 november 2019, 22.29.

https;//tribunnews.com diunduh 3 desember 2019, 19.00 . 